\title{
REPORT OF THE BUSINESS MEETING, FRIDAY 19 AUGUST 1994
}

\author{
MARIAN SCOTT, ${ }^{1}$ DOUG HARKNESS ${ }^{2}$ and A. J. T. JULL ${ }^{3}$
}

\section{Item 1: Proposal for the formation of a Radiocarbon Society}

Proposed: Renee Kra

Seconded: Austin Long

Prior to the meeting, a draft proposal had been circulated amongst all conference participants putting forward the idea of an association of laboratories. One of the main reasons behind the proposal was the present financial difficulties that the journal RADIOCARBON is now experiencing. There was a wide-ranging discussion that centered on two main themes: 1 ) the financial requirements of the journal; and 2) the formation of the "Radiocarbon Society", which might be a mechanism to provide the necessary financial support for the journal, in addition to binding the radiocarbon community in various cooperative deeds and projects.

Two motions were put forward: 1) the editors of RADIOCARBON prepare a detailed business plan, exploring different options for financial viability, and showing how revenue generated from specific sources would cover the existing deficit. This was accepted by the meeting; and 2) that an association, which would engender environmental isotope research, and both individuals and laboratories, should be created; that by-laws should be drawn up for approval, and that honorary officers should be elected democratically, but that the day-to-day management should be carried out by full-time staff, most likely based at the Tucson office of RADIOCARBON. This motion was also approved by the meeting. The editors agreed to distribute the financial report and the by-laws to the participants at a later date.

Item 2: Proposal that a working group be established to discuss the detail and validation of the 1993 calibration and that this group should represent both users and the producer community

\section{Proposed: Mike Baillie \\ Seconded: Sheridan Bowman, Erle Nelson, Janet Ambers, Gordon Cook and Jan Lanting}

It was generally agreed that changes introduced in the 1993 calibration volume and, in particular, the data used in CALIB 3.0 had not been explained fully or justified to the user, and that a wider discussion of the reasons for the changes and their validity should be held. It was put forward that the status of the 1993 calibration was unclear, given that the 1986 calibration had previously been presented to the users as the accepted data, so that users were now in doubt as to which calibration data set to use. It was, however, pointed out that it was unreasonable not to expect changes and improvements, but the motion that a wider discussion was required and that a working group be established was accepted by the meeting.

\footnotetext{
${ }^{1}$ Department of Statistics, University of Glasgow, University Gardens, Glasgow G12 8QW, Scotland ${ }^{2}$ NERC Radiocarbon Laboratory, Scottish Enterprise Technology Park, East Kilbride, G75 0QF, Scotland

${ }^{3}$ AMS Laboratory, Department of Physics, University of Arizona, Tucson, Arizona 85721 USA
} 


\section{Item 3: Location of the 16th International Radiocarbon Conference in 1997}

Four cities/institutions made bids to hold the next conference. They were, in order of presentation:

Beijing (proposed by Zhiyu Guo), Groningen (proposed by Wim Mook), Cracow (proposed by Mieczysław Pazdur) and St. Petersburg (proposed by Ganna Zaitseva). It was proposed and accepted by the meeting that a postal ballot should be held, in this way, allowing bidders an opportunity to confirm their willingness to hold the conference and to provide more specific details of their bids (including host organization, local organizing committee and proposed time of conference). The organizers of the 15th International Conference undertook to mail all conference participants and those who had participated in the previous conference in Tucson with voting papers by the end of 1994, and that an announcement as to the successful outcome would be made in RADIOCARBON as soon as possible in 1995.

\section{Item 4: Obituaries}

The meeting was saddened to learn of the deaths of several members of the ${ }^{14} \mathrm{C}$ community. Short but touching tributes were given for:

Hans Suess (by Meyer Rubin)

Jean-Charles Fontes (obituary prepared by Peter Fritz, Roberto Gonfiantini and GianMaria Zuppi and given by Doug Harkness)

Ulrich Siegenthaler (by Heinz Hugo Loosli).

Previously, during the Calibration session of the main conference, Bernd Kromer gave an appreciation of the life of Bernd Becker.

\section{Item 5: Any other competent business}

A number of items were raised under this heading.

It was noted that there were already two expressions of interest in holding the ${ }^{14} \mathrm{C}$ conference in the year 2000, from Israel and Australia.

It was also announced that a third conference in the series ${ }^{14} \mathrm{C}$ and Archaeology was being planned, and that it would be in 1997 or 1998, most likely in Lyon, France.

Finally, the meeting was reminded that the IAEA is continuing to offer Analytical Quality Control Services by providing carbon isotope reference materials and preparing new reference materials.

The meeting and conference were then closed by Doug Harkness on behalf of the local organizers, who thanked all participants for coming.

All proposers and seconders were asked for comments on the items and their suggestions have been incorporated.

\section{Post-conference addenda:}

\section{Item 1: RADIOCARBON Update}

The years 1994 and 1995 were most tumultuous for RADIOCARBON. We bid "farewell" to these two years, and look forward to a robust 1996. We charted our course along the way (Long, Kra and Jull 1994; Long, Jull and Kra 1994), so that this chronicle of our speedy recovery should not come as a surprise. Briefly, the steps leading to health and prosperity can be summarized as follows: 
1. Aggressive marketing techniques

2. Restructuring the journal

3. Many helping hands from the radiocarbon community

Above all, our new Consulting Editor, Tim Jull, has given us invaluable support. Through his efforts, we were able to invite Kimberley Tanner (now Kimberley Tanner Elliott) to rejoin our staff and hasten the publication of our long-delayed issues. And now that I have rejoined the "team", we should be able to honor our commitments and deliver our beloved journal to faithful subscribers and contributors. This was a hard lesson for RADIOCARBON; we will apply it well and keep a vigilant eye in all directions at all times.

Renee S. Kra

\section{REFERENCES}

Long, A., Jull, A. J. T. and Kra, R. S. 1994 From the Editors: To Our Friends (Continued). Radiocarbon 36(3): iii. Long, A., Kra., R. S. and Jull, A. J. T. 1994 From the Editors: To Our Friends. Radiocarbon 36(2): iii.

\section{Item 2: 1993 Calibration Revisions}

At the 1994 International Radiocarbon Conference in Glasgow, a group of interested individuals proposed that a sub-committee should address the issue of the 1993 revision of the 1986 Belfast and Seattle calibration curves and report back at the next appropriate meeting. It is now clear that there are substantial grounds for questioning the correction to the Belfast 1986 data as put forward by Pearson and Qua (1993) and some relevant information appears in McCormac et al. (1995). Currently several workers, on various grounds, believe that the 1986 Belfast calibration data are more appropriate than the corrected data of 1993.

Anyone with views, either for or against the proposition regarding the Belfast 1986/1993 debate, or relevant to the question of ${ }^{14} \mathrm{C}$ uniformity, should address his or her comments in the first instance to the Palaeoecology Centre, School of Geosciences, Queen's University, Belfast BT7 1NN, Northern Ireland, U.K. It is envisaged that a meeting to discuss the issues and to arrive at a resolution will take place in early 1996.

\section{G. L. Baillie, Palaeoecology Centre, The Queen's University, Belfast}

\section{REFERENCES}

McCormac, F. G., Baillie, M. G. L., Pilcher, J. R., Jirikowic, J. L. and Kalin, R. M. 1995 Location-dependent differences in the ${ }^{14} \mathrm{C}$ content of wood. Radiocarbon, this issue.

Pearson, G. W. and Qua, F. 1993 High-precision ${ }^{14} \mathrm{C}$ measurements of Irish oaks to show the natural ${ }^{14} \mathrm{C}$ variations from $\mathrm{AD}$ 1840-5000 BC: A correction. In Stuiver, M., Long, A. and Kra, R. S., eds., Calibration 1993. Radiocarbon 35 (1): 105-123.

Item 3: The 16th International Radiocarbon Conference will be in Groningen, The Netherlands. Wim Mook and Hans van der Plicht are in charge of arrangements for the 1997 meeting. 